\title{
DESTRUKSI ARCA-ARCA MASA SRIWIJAYA: PETAKA SOSIAL PADA MASA KESULTANAN PALEMBANG
}

\section{The Destruction of Sriwijaya Periode Sculptures: The Social Disaster in The Sultanate of Palembang Era}

\author{
Retno Purwanti \\ Balai Arkeologi Sumatera Selatan \\ Jalan Kancil Putih, Lr. Rusa, Demang Lebar Daun, Palembang \\ E-mail: nretnopurwanti@yahoo.com
}

\begin{abstract}
Kadatuan Sriwijaya is a realm from the 7th-14th century AD. Based on the inscription and sculptures found in Palembang, it can be seen that the official religion of Sriwijaya is Buddhism. However, at the same time Hinduism was followed by some people. A lot of the Buddhist and Hindu sculptures found in Palembang are in a state of incomplete. A number of sculptures were found without a head, hands, feet or body. The non-complience of these sculptures raises questions as to the cause of their damage. Is the damage to the sculptures caused by natural factors or human factors? The research objective was to determine the factors that caused the damage to the sculptures using descriptive research methods. Based on the analysis of the fragments of the sculpture's fragments, it can be assumed that the cause damage is a human factor.
\end{abstract}

Keywords: destruction, sculptures, Swiwijaya

\begin{abstract}
Abstrak
Kadatuan Sriwijaya adalah sebuah kerajaan dari abad ke-7 hingga ke-14 Masehi. Berdasarkan prasasti dan arca-arca di Palembang terlihat, bahwa agama resmi Sriwijaya adalah Buddha. Namun, pada saat yang sama agama Hindu juga dianut oleh sebagian masyarakat. Banyak arcaarca yang ditemukan di Palembang dalam keadaan tidak lengkap. Sejumlah arca ditemukan tanpa kepala, tangan, kaki atau badan. Ketidaklengkapan arca-arca ini menimbulkan pertanyaan tentang penyebab kerusakannya. Apakah kerusakan arca disebabkan oleh faktor alam atau manusia? Tujuan penelitian adalah untuk mengetahui faktor-faktor penyebab kerusakan arca dengan menggunakan metode penelitian deskriptif. Berdasarkan analisis pecahan-pecahan arca tersebut, dapat diduga bahwa penyebab kerusakannya adalah faktor manusia.
\end{abstract}

Kata kunci: destruksi, arca, Sriwijaya

\section{PENDAHULUAN}

Di Palembang ditemukan data arkeologi dari masa kedatuan ${ }^{1}$ Sriwijaya sampai dengan masa Kolonial, baik berupa artefak, ekofak maupun fitur (Kusumohartono 1992). Artefak yang ditemukan di Palembang, antara lain prasasti, arca, manik-manik, sisa-sisa papan perahu, cetakan stupika, stupika tanah liat, bandul jaring, dan pecahan

\footnotetext{
${ }^{1}$ Dalam prasasti-prasasti dari masa Sriwijaya disebutkan istilah datu untuk penguasa Sriwijaya dan bukan raja. Berdasarkan fakta tersebut sudah selayaknya lembaga pemerintahannya disebut dengan istilah kedatuan. Kedatuan berarti tempat para datu. Pada masa kini, istilah kedatuan masih diterapkan, Kedatuan Luwu di sulawesi Selatan dan Kedatun Lampung.
} 
keramik. Arca-arca yang ditemukan di Palembang berasal dari agama Buddha dan Hindu. Lokasi penemuan arca-arca tersebut adalah situs Bukit Siguntang, Sarangwati, Gedingsuro, Pagaralam, Kedukan Bukit, Kandangkawat, Benteng Kuto Besar, dan situs Monpera. Arca-arca tersebut (Purwanti, Retno dan Eka Asih Putrina Taim 1995) sebagian besar ditemukan tidak dalam keadaan utuh, bahkan banyak yang ditemukan hanya bagian kepalanya saja. Meskipun demikian, dari gaya seni dan konteks temuannya dapat diduga, bahwa arca-arca tersebut berasal dari masa Sriwijaya (abad ke-7 - ke-9 M). Banyaknya arca-arca yang ditemukan dalam keadaan tidak utuh menimbulkan permasalahan mengenai penyebab kerusakannya. Dalam sejarah kebencanaan, Palembang tidak tercatat sebagai daerah yang pernah dilanda bencana alam pada masa Sriwijaya. Dengan demikian, ada satu dugaan bahwa arca-arca tersebut dirusak oleh manusia. Apabila dugaan tersebut benar, maka ada dua pertanyaan yang dapat diajukan, yaitu siapa yang merusak dan kapan perusakan itu dilakukan?

Dengan mengacu pada permasalahan dan pertanyaan di atas, tujuan penelitian ini ialah untuk mengetahui pelaku dan waktu perusakan arca-arca masa Sriwijaya. Metode yang diterapkan untuk mencapai tujuan penelitian adalah deskriptif analisik berdasarkan kajian literatur. Adapun proses yang dilakukan terdiri dari pengumpulan data, analisis data, dan interpretasi atau penyajian hasil analisis. Langkah pertama adalah pengumpulan data melalui sumber primer dan sekunder. Sumber primer diperoleh dari survei terhadap arca-arca masa Sriwijaya yang sekarang disimpan di Museum Sriwijaya, Museum Sultan Mahmud Badaruddin II dan Museum Balaputera Dewa. Sementara itu, sumber sekunder diambil seluruhnya dari studi literatur, baik berupa laporan penelitian, artikel dan buku referensi. Langkah kedua yaitu melakukan analisis terhadap arca-arca masa Sriwijaya untuk mengidentifikasi bagian-bagian yang mengalami kerusakan. Data ini kemudian disinkretiskan dengan data sekunder melalui pendekatan sejarah sehingga dapat diketahui pelaku dan waktu perusakannya.

\section{PEMBAHASAN}

\section{Arca Buddha Bukit Siguntang}

Arca Budha yang terbuat dari batu granit ini ditemukan dalam keadaan tidak utuh dan terbagi menjadi beberapa bagian. Pada tahun 1920 yang ditemukan hanya bagian kepalanya saja, yang kemudian dikirim ke Batavia. Pada tahun 1928 ditemukan bagian torso dan bagian kaki. Setelah direkonstruksi beberapa fragmen arca batu granit tersebut, ternyata berasal dari satu arca Budha berukuran besar. Kepala arca ini awalnya sudah disimpan di Museum Nasional Jakarta, yang kemudian disatukan kembali dengan bagian badannya, sehingga dapat diketahui ukurannya, yakni $377 \mathrm{~cm}$ (Schnitger, F.M. 1937). Sekarang arca ini terdapat di halaman Museum Sultan Mahmud Badaruddin, Palembang (Purwanti, Retno 2016). Arca yang dipahatkan dalam posisi berdiri ini, berdasarkan gaya seninya, diduga berasal dari abad ke-2-4 (Suleiman, Satyawati 1981). Namun, ada pendapat lain yang mengemukakan bahwa arca Budha dari Bukit Siguntang ini berasal dari abad ke-6-7 Masehi (Shuhaimi, Nik Hasan 1979). Arca digambarkan 
memakai jubah transparan berlipat-lipat menutupi kedua bahunya, berambut keriting dan bersanggul (usnisa) dan di dahinya terdapat bulatan (urna). Ciri-ciri ikonografi pada arca menunjukkan gaya Amarawati yang berkembang di India Selatan pada sekitar abad ke-2-5 Masehi. Namun, gaya ini masih tetap berkembang di Sri Lanka sampai abad ke-8 Masehi. Atas dasar ini, maka diperkirakan arca Budha dari Bukit Siguntang ini berasal dari sekitar abad ke-7-8 Masehi (Gambar 1).

Di bagian lembah Bukit Siguntang juga ditemukan fragmen arca yaitu bagian kepala Bodhisattwa. Kepala arca ini digambarkan dengan rambut yang tersisir rapi dengan ikatan seutas pita yang berhiaskan kuntum bunga. Sebagaimana halnya arca Budha dari batu granit, bagian badan arca ini ditemukan di tempat yang berjauhan tetapi masih di daerah bukit Siguntang. Bagian badannya digambarkan memakai kain dengan lipatan seperti wiru di bagian tengah. Kain yang dikenakannya itu diikat dengan sabuk dari kain yang lebar (Bambang Budi Utomo 2016).

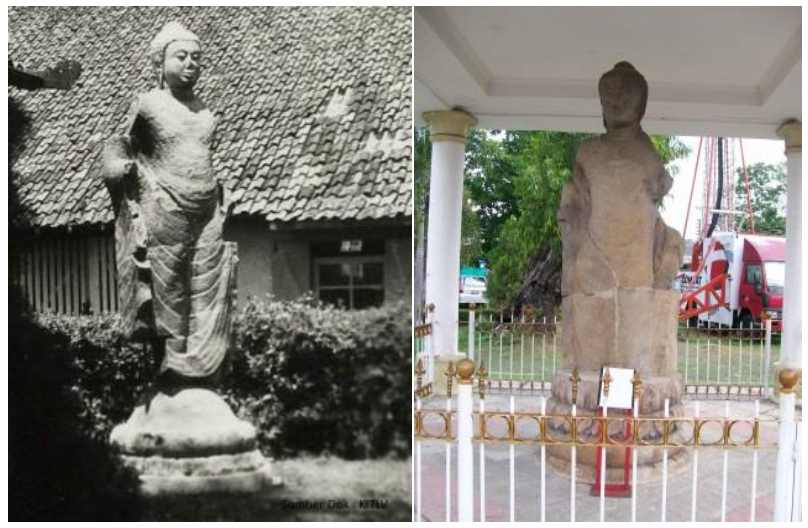

Gambar 1. Arca Buddha Bukit Siguntang Sumber: dokumen KITLV dan Balai Arkeologi Sumatera

Selain arca Buddha tersebut, di Bukit Siguntang juga ditemukan arca-arca lain dari bahan batu maupun perunggu. Sebagian besar arca-arca saat ditemukan sudah dalam keadaan tidak utuh. Adapun arca-arca tersebut adalah arca Buddha dari perunggu, tingginya $16,5 \mathrm{~cm}$. Saat ditemukan kedua tangan arca ini patah mulai dari bagian siku. Arca lainnya adalah pecahan kepala Bodhisattwa (2 arca) dan 2 fragmen arca Awalokiteswara (Schnitger, F.M. 1937).

\section{Arca Bodhisattva}

Arca ini sekarang disimpan di ruang koleksi Museum Sriwijaya Palembang. Lokasi temuan di Situs Muarajambi, Kecamatan Marosebo, Kabupaten Muaro Jambi, Provinsi Jambi. Ukuran arca tinggi $90 \mathrm{~cm}$, lebar 35,5 cm, dan tebal 15,5 cm. Kondisi arca dalam keadaaan tidak utuh, bagian kepala tidak ada, kedua tangan patah. Arca digambarkan dalam sikap berdiri tegak dan mengenakan jubah tipis, panjang sampai pada mata kaki. Jubah tersebut digambarkan menutupi bagian kedua bahu, namun pada 
bagian depannya melengkung ke depan sehingga menutupi bagian sisi kanan dan kiri dari bahu hingga mata kaki.

Postur tubuh digambarkan ramping. Pada permukaan badan terdapat goresangoresan bekas benda tajam. Berdasarkan cara penggambaran arca, arca Buddha ini mirip dengan arca Buddha yang ditemukan di Vieng Sa, sebelah utara Semenanjung Tanah Melayu. Arca-arca tersebut mengambil gaya seni dari India Utara dan berasal dari abad ke-7-8 Masehi (Bambang Budi Utomo 2016).

\section{Fragmen Tangan Arca}

Fragmen tangan arca ini merupakan bagian pangkal lengan (bahu) sampai di atas siku tangan kanan. Panjang $23 \mathrm{~cm}$, diameter bagian pangkal lengan $11 \mathrm{~cm}$, dan diameter bagian siku $6 \mathrm{~cm}$. Bagian siku kanan ini digambarkan ditekuk ke atas dan tampak memegang benda. Bagian lengan atas mengenakan kelat bahu berbentuk bunga dan di atasnya terdapat rangkaian bunga yang diuntai. Rangkaian bunga ini kemungkinan merupakan upawita (tali kasta). Dengan adanya upawita ini, maka dapat diketahui bahwa pecahan tangan ini merupakan bagian dari lengan arca dewa/dewi. Fragmen tangan arca ini sekarang disimpan di ruang koleksi museum Sriwijaya Palembang (Gambar 2).

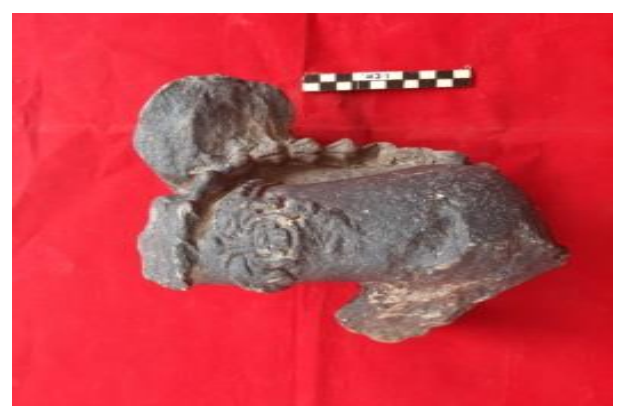

Gambar 2. Fragmen tangan arca Sumber: Dokumen Museum Sriwijaya, 2020

\section{Fragmen Kepala Arca}

Fragmen kepala arca pertama digambarkan dengan tatanan rambut menyerupai sanggul, namun bagian sanggul ini terpangkas. Jamang tidak tampak pada bagian kening. Arca setinggi $21 \mathrm{~cm}$ ini digambarkan dengan bentuk wajah yang mirip dengan arca-arca Bodhisattwa dengan gaya seni Syailendra yang berkembang pada abad ke-8-9 Masehi (Bambang Budi Utomo 2016; Shuhaimi, Nik Hasan 1979). Fragmen kepala arca kedua juga dibuat dari batu dalam keadaan aus dan disimpan di ruang koleksi museum Balaputera Dewa dengan nomor registrasi 04.15. Ukuran arca adalah tinggi $22 \mathrm{~cm}$, lebar $24 \mathrm{~cm}$ dan tebal $12 \mathrm{~cm}$. Bagian wajah sudah rusak dan bagian sanggul sudah patah. Bagian belakang kepala arca sangat aus, tetapi masih menyisakan goresan pilinan rambut. Telinga kanan masih tampak jelas, namun telinga kiri hilang. Bagian hidung dan dagu tidak ada. Mata masih tampak, meskipun aus. 
Selain kedua fragmen arca tersebut, ada satu fragmen kepala arca yang sekarang disimpan di Museum Sriwijaya. Arca dalam keadaan aus bagian wajahnya. Arca ini ditemukan di Sungai Kedukan pada tahun 1993. Arca digambarkan dengan rambut disanggul berbentuk jatamakuta dengan jamang di bagian kening. Pada sanggul bagian depan terdapat relief arca Amitabha. Dengan adanya relief Amitabha dapat diidentifikasikan tokoh yang digambarkan, yaitu Avalokitesvara.

\section{Fragmen Arca Ganesha}

Fragmen arca ganesha kondisinya bagian kepala sampai leher sudah hilang. Bagian tangan kanan dan kiri hilang. Begitu pun dengan kaki bagian kanan. Padmasana juga tidak utuh. Arca digambarkan dalam sikap duduk di atas padmasana dengan kaki kiri dilipat dan telapak kaki ke arah atas, mirip dalam sikap bersila. Kaki kiri masih tampak mengenakan gelang kaki. Lengan kanan dan kiri mengenakan gelang lengan (kelat bahu) berhias motif bunga. Gelang lengan juga masih tampak meski tidak utuh lagi. Kalung tampak menjuntai sampai dada dan digambarkan dengan motif bunga.

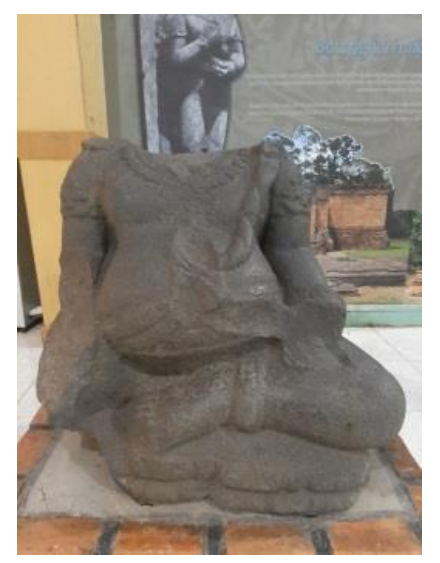

Gambar 3. Fragmen arca Ganesha Sumber: Dokumentasi penulis, 2020

Kain yang dikenakan berupa kain yang diikat dengan selendang (sampur), yang kedua ujungnya menjuntai ke arah kedua kaki dan menyentuh padmasana. Tali kasta digambarkan polos dari bahu kiri sampai ke perut (Gambar 3).

\section{Fragmen Arca Buddha}

Arca ini ditemukan di situs Gedingsuro, Palembang (Schnitger, 1937). Kondisi arca dalam keadaan tidak utuh, bagian kepala, lengan dari siku sampai telapak tangan hilang. Begitupun bagian kedua kaki juga hilang. Tinggi arca $108 \mathrm{~cm}$. Lokasi arca sekarang ada di gedung pamer museum Sriwijaya, Palembang. Arca digambarkan dalam sikap berdiri tegak. Pakaian yang dikenakan berupa kain tipis (jubah) yang panjangnya sampai di atas mata kaki. Jubah menutupi kedua bahu dana melengkung ke arah depan. Arca ini sudah disebutkan dalam buku Schnitger yang diterbitkan pada tahun 1937 (Schnitger, F.M. 1937). Menurut Schnitger, penggambaran arca Buddha ini mirip yang 
ada di Viang Sa. Berdasarkan gaya seninya, arca ini berasal dari abad ke-7-8 Masehi (Gambar 4, kiri).

Fragmen arca Buddha kedua kondisinya juga tidak utuh, karena bagian kepala sampai leher, kedua tangan, dan kaki hilang. Arca digambarkan dalam sikap berdiri. Kain yang dikenakan tidak simetris, karena kain hanya sampai batas lutut pada kaki kiri, sedangkan di bagian kanan sampai di atas pergelangan kaki. Kain ini dilipat di bagian tengah depan sehingga membentuk lipatan seperti dua pita. Untuk mengikat kain digunakan ikat pinggang dengan motif hias bunga. adapun sampur (selendang) disimpulkan di bagian pinggul. Tinggi arca $118 \mathrm{~cm}$. Lokasi arca sekarang ada di gedung pamer museum Sriwijaya, Palembang (Gambar 4, kanan). Berdasarkan kain yang dikenakan, arca termasuk arca dengan gaya seni Syailendra dari abad ke-8-9 Masehi.

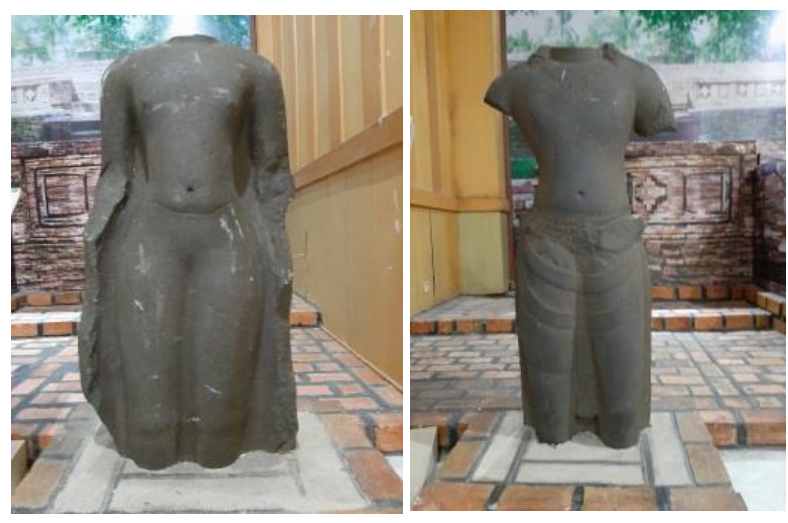

Gambar 4. Fragmen arca Buddha Sumber: Dokumentasi penulis, 2020

Selain arca-arca tersebut di Situs Gedingsuro juga ditemukan arca-arca Buddha yang dibuat dari bahan perunggu oleh para penggali liar. Jumlah yang ditemukan puluhan, namun hanya empat arca yang masih bisa diselamatkan dan teridentifikasi. Tinggi arca antara 4,7 cm $-10 \mathrm{~cm}$. Keempat arca dalam kondisi tidak utuh lagi. Bagian yang hilang adalah tangan dan kaki.

\section{Destruksi Arca-arca di Luar Palembang}

Di luar arca-arca yang ditemukan di Palembang, terdapat arca-arca dari masa Sriwijaya yang ditemukan di luar Palembang. Arca Awalokiteswara dari Situs Binginjungut, Kecamatan Muarakelingi, Kabupaten Musirawas ditemukan dalam kondisi tidak utuh, karena dua tangan kanan hilang. Begitupun, dengan satu tangan kiri. Arca ini dibuat dari batu dengan tinggi $172 \mathrm{~cm}$. Selain itu ada arca Buddha dari situs Tingkip, Kecamatan Surulangun, Kabupaten Musirawas Utara. Arca ini tingginya 172 cm dan tangan bagian kiri hilang.

Arca-arca lainnya yang ditemukan di luar Palembang adalah arca Camundi dari Candi 3, Situs Bumiayu, Kabupaten Pali. Arca dibuat dari tanah liat dan hanya menyisakan bagian torso. Bentuk torso berwujud perempuan dengan mengenakan upawita berbentuk tengkorak. Tinggi arca $44 \mathrm{~cm}$. Arca lainnya ialah fragmen arca Siwa 
dari tanah liat. Bagian kepala dan tangan kiri hilang, bagian dada pecah dan bagian bawah hilang. Tinggi arca $23 \mathrm{~cm}$. Arca Siwa dari Candi 1 Bumiayu saat ditemukan dalam keadaan rusak. Bagian kepala, wajah dan dada rusak. Bagian sandaran arca patah, begitupun bagian pergelangan tangan kanan depan, lengan kiri depan dan tangan kiri belakang serta lutut kanan.

Berdasarkan bahan pembuatannya dapat diketahui, bahwa arca-arca yang ditemukan di wilayah Sumatera Selatan dibuat dari batu, logam dan tanah liat. Dari sejumlah temuan arca tersebut, temuan arca di situs Bukit Siguntang hampir semuanya dalam keadaan tidak utuh. Satu arca terbesar yang ditemukan di situs ini adalah arca Buddha. Dalam catatan Schnitger arca ini tingginya $377 \mathrm{~cm}$ seperti tampak pada gambar 1 sebelah kiri, termasuk padmasana. Pada gambar terlihat bagian kaki masih tampak lebih panjang sampai mata kaki, serta kaki sebelah kiri hanya hilang dari bagian atas mata kaki, hanya sekitar setinggi $10 \mathrm{~cm}$. Jubah yang dikenakan arca juga masih tampak menjuntai sampai ke bawah. Hal ini berbeda jauh dibandingkan dengan gambar kaki arca yang tampak sekarang seperti yang tampak pada gambar 1 di bagian kanan. Saat dilakukan pengukuran, tinggi arca ini sekarang tinggal $277 \mathrm{~cm}$. Dengan demikian mengalami penyusutan hampir 1 meter.

Dengan membandingkan kondisi arca pada saat direkonstruksi pada tahun 1937 dan sekarang, maka dapat diduga bahwa pengurangan tinggi arca dan beberapa bagian arca tidak ditemukan lagi, dapat diduga bahwa terjadi "pemangkasan" pada bagianbagian arca yang hilang untuk penempatan arca pada di lokasi baru, yaitu di halaman museum Sultan Mahmud Badaruddin II. ${ }^{2}$ Kerusakan ini merupakan kerusakan kedua yang dialami arca. Adapun kerusakan pertama disebabkan karena proses penghancuran yang dilakukan oleh Sultan Abdurrahman (Akib, RH. Tanpa tahun). Perusakan itu dilakukan terhadap bangunan suci di situs Bukit Siguntang (Purwanti, Retno 2016).

Perusakan bukit tertinggi di Palembang dan merupakan tempat peribadatan dari masa kedatuan Sriwijaya ini dilakukan kemungkinan dengan tujuan agar tidak terjadi perbuatan syirik di areal ini. Sultan ini berkuasa pada tahun 1659-1706 dan merupakan penguasa pertama di Palembang yang bergelar sultan (Rahim, Husni 1998). Pada awal masa pemerintahannya, sultan mengundang ulama-ulama Arab yang tinggal di Aceh untuk mengajarkan agama Islam di lingkungan istana. Tujuan lainnya yaitu untuk melakukan pemulihan perekonomian Palembang setelah keratonnya dibumihanguskan oleh Belanda pada tahun 1659 dan perang saudara untuk memperebutkan kekuasaan (Azra, Azyumardi 2005). Ada dugaan ulama sultan inilah yang menyarankan untuk melakukan perusakan terhadap arca-arca di situs Bukit Siguntang ${ }^{3}$.

Proses penghancuran peradaban/budaya Hindu-Buddha di Palembang pada masa pemerintahan Susuhunan Abdurrahman ini juga disampaikan oleh A. Sulaiman Maruff pada tahun 1993 di dalam artikelnya, berjudul "Sejarah Hari Jadi Kota Madia Palembang” (A. Suleiman Maruff 1993). Disebutkan juga, bahwa semua arca yang ada

\footnotetext{
${ }^{2}$ Sekarang arca telah dipindahkan ke Museum Sriwijaya dan ditempatkan di depan pintu masuk museum.

${ }^{3}$ Peristiwa perusakan bangunan di Bukit Siguntang juga masih diingat oleh beberapa ulama di Palembang sekarang.
} 
di rumah-rumah orang Islam diwajibkan untuk dibuang atau dimusnahkan, sehingga banyak penganut Islam membuangnya di muara Sungai Sekanak dan muara Sungai Tawar, Palembang. Selain dibuang ke sungai, bagi warga Palembang pemilik arca yang sudah menganut Islam, dan tinggalnya tidak di tepi sungai, maka arca-arca itu dibuang ke rawa-rawa atau dikuburkan di dalam tanah.

Selain karena faktor manusia seperti yang telah diuraiakan di atas, kerusakan arca-arca yang ditemukan di Palembang disebabkan karena alih fungsi situs-situs dari masa Sriwijaya oleh para penguasa Islam. Alih fungsi situs-situs masa Sriwijaya yang sebagian besar merupakan bangunan candi, pada masa kemudian digunakan sebagai lokasi pemakaman para penguasa Palembang. Contoh-contoh situs tersebut adalah Sabokingking, Gedingsuro, Candi Angsoka, dan Kompleks Makam Sultan Mansyur (Purwanti, Retno 2004). Proses alih fungsi situs ini tidak hanya merusak bangunan candi yang terbuat dari bata, namun juga arca-arca yang terdapat di dalamnya.

Proses alih fungsi situs ini tidak hanya terjadi di masa lalu, namun juga pada masa kemerdekaan. Penemuan arca-arca di lokasi pembangunan sering terjadi. Penggalian tanah di lokasi Monumen Penderitaan Rakyat, di tengah kota Palembang, ternyata menampakungkapkan arca torso yang sekarang disimpan di museum Sriwijaya. Hal ini juga terjadi pada arca-arca perunggu yang ditemukan di dalam Kompleks benteng Kraton Kuto Besar. Berdasarkan pada masa pemerintahan tokoh-tokoh yang dimakamkan, dapat diperkirakan bahwa proses alih fungsi candi menjadi makam ini terjadi pada kurun waktu antara abad XVI-XVII Masehi (Hanafiah, Djohan 1989).

Sementara itu, kerusakan fragmen kepala arca dan tangan arca kemungkinan juga terjadi karena disengaja. Lokasi penemuan dari dalam sungai atau permukiman penduduk yang dekat dengan aliran sungai, memungkinkan bahwa pecahan-pecahan arca tersebut terdeposit di lokasi penemuan karena proses pembuangan.

Kerusakan arca-arca masa Sriwijaya juga terjadi karena candi dimana arca-arca biasa ditempatkan di dalam ruang-ruang di dalamnya sudah ditinggalkan oleh pemeluknya. Karena tidak dipelihara dan semua candi dibuat dengan menggunakan bata, maka candi-candi tersebut runtuh, karena proses alam. Contoh untuk candi-candi seperti ini adalah candi di situs Bumiayu, Binginjungut dan Tingkip. Kerusakan parah terjadi pada arca-arca yang terbuat dari tanah liat.

\section{SIMPULAN}

Berdasarkan hasil penelitian terhadap arca-arca yang ditemukan di Palembang sejak masa kolonial sampai sekarang, sebagian besar dalam keadaan tidak utuh. Ketidakutuhan arca-arca yang hanya ditemukan diduga sengaja dirusak pada masa pengaruh Islam mulai berkembang di Palembang. Perusakan ini diperkirakan karena ada kekhawatiran pihak Penguasa (Sultan) Palembang akan perilaku syirik warganya yang baru memeluk Islam. Selain itu, kerusakan mungkin juga diakibatkan candi yang menaungi arca mengalami keruntuhan. Kerusakan juga disebabkan karena proses pembangunan pada masa-masa Kemerdekaan. Perusakan arca secara sengaja diduga diawali sekitar abad ke-17 Masehi. 


\section{DAFTAR PUSTAKA}

A. Suleiman Maruff. 1993. "Sejarah Hari Jadi Kota Palembang.” Sriwijaya Post, 1993.

Akib, RH. Tanpa tahun. "50 Tahun Kota Praja Palembang.” Dalam . Palembang: Rhama.

Azra, Azyumardi. 2005. Jaringan Ulama Timur Tengah dan Kepulauan Nusantara Abad XVII \& XVIII Akar Pembaruan Islam Indonesia. Revisi. Jakarta: Prenada Media.

Bambang Budi Utomo. 2016. Pengaruh Kebudayaan India dalam Bentuk Arca di Sumatra. 1 ed. 1. Jakarta: Yayasan Pustaka Obor Indonesia.

Hanafiah, Djohan. 1989. Kuto Besak. Upaya Kesultanan Palem $\neg$ bang menegakkan Kemerdekaan. Jakarta: C.V. Haji Mas Agung.

Kusumohartono, B.M.H. 1992. "Potensi Lingkungan Regional dan Pertumbuhan Peradaban Kuna di Palembang." Dalam Himpunan Hasil Penelitian Arkeologi di Palembang, 2843. Palembang.

Purwanti, Retno. 2004. “Situs-situs Islam di Palembang." Dalam Jati Diri Yang Terlupakan Naskah-Naskah Kuna Palembang, 1 ed. Depok: Yayasan Naskah Nusantara.

— 2016. "Bukit Siguntang: Peranannya Dalam Agama Buddha Pada Masa Sriwijaya." Forum Arkeologi, No. 1, 29 (April): 11-20.

Purwanti, Retno dan Eka Asih Putrina Taim. 1995. "Situs-situs Arkeologi di Kota Palembang: Persebaran dan Keletakannya.” Berkala Arkeologi XIV-Edisi Khusus: 95-99.

Rahim, Husni. 1998. Sistem Otoritas \& Administrasi Islam Studi Tentang pejabat Agama Masa kesultanan dan Kolonial di Palembang. Jakarta: Logos.

Schnitger, F.M. 1937. The Archaeology of Hindoo Sumatra. Leiden: E.J. Brill.

Shuhaimi, Nik Hasan. 1979. “The Bukit Siguntang,” 38, III (2).

Suleiman, Satyawati. 1981. Sculptures of Ancient Sumatra. Jakarta: Pusat Penelitian Arkeologi Nasional.

\section{HASIL DISKUSI}

\section{Tidak Ada Pertanyaan}

